\title{
Islanders of South Korea: Culture, Climate Change, and Traditional Ecological Knowledge
}

\author{
Samantha Chisholm Hatfield \\ Oregon State University Oregon Climate Change Research \\ Institute, USA \\ shatfield@coas.oregonstate.edu
}

\author{
Sun-Kee Hong \\ Institution for Marine \& Island Cultures, Mokpo National \\ University, Korea \\ landskhong@gmail.com
}

Publication Information:

Received 23 December 2017, Accepted 27 December 2017, Available online 19 January 2018

doi: 10.21463/jmic.2017.06.2.05

\begin{abstract}
Selected Island populations of South Korea were interviewed and landscapes surveyed in the Southwestern ocean region to discern what cultural changes they had noted in response to environmental changes possibly due to climate change impacts. Utilizing Traditional Ecological Knowledge (TEK) methodology, cultural behaviors and patterns of island populations were easily identified, along with historical information of changes occurring for islanders in the areas of lifestyle, adaptation, and utilization of natural resources. This TEK information is being fragmented and is at risk within the current structure of island system operations.
\end{abstract}

\section{Keywords}

Traditional Ecological Knowledge, TEK, Traditional Knowledge, TK, Indigenous Knowledge, IK, South Korea, Culture, Multidisciplinary Research, Interdisciplinary research, Korean Islands

\section{Introduction}

Traditional Korean oral history seems to echo patterns that have been documented for Native Americans, and can illustrate cultural traditions. Many of these have been rooted in landscape situations, stemming from natural resources that were available. Traditional cultural aesthetics illustrated in artwork is a universal theme, but there remains a need for information regarding Korean culture, particularly with the recent rise in popularity of Korean related culture and items, termed the "hallyu wave", (Kim, Ryoo 2007) has been on the uptick in worldwide trends. 
Traditional Korean housing is called a hanok, and were developed to emphasize the surrounding environment. Traditional hanok houses have structured systems that utilize the natural beauty and environmental elements without causing resource destruction (Kim, 2006). The popularity of such housing systems, and their design harks to a cultural system that honors and maintains its close tie to the environment, particularly on islands. Similarly, roads, walls, and other structures built from local resources that are associated with being traditionally "Korean" illustrate a non-verbal identity that Korean people have, and the source of pride that is woven throughout Korean culture. Many take these commonplace structures for granted, not considering how visual representations bring a collective sense of identity and culture when viewed on a daily basis; these structures provide a sense of cultural pride and dignity setting them apart from imported goods and services which would encourage assimilation practices.

Though culture is evident widely across the South Korea mainland landscape, it is rich and vibrant through the TEK that is expressed in island cultures. Islanders are vital to the economic welfare, and arguably a foundational cornerstone of, and for maintaining, Korean culture. Nine islands were visited for this research project in search of documentation of TEK that exists and is evident in island cultures for the wellbeing and maintenance of culture as well as any evidence for climate change events that may be impacting culture in any manner. Islands visited for this research included: Cheonsando, Yeoseodo, Uido, Chodo, Wolmido, Jeju, Udo, Amtae-do, Saengildo. (see Appendix)

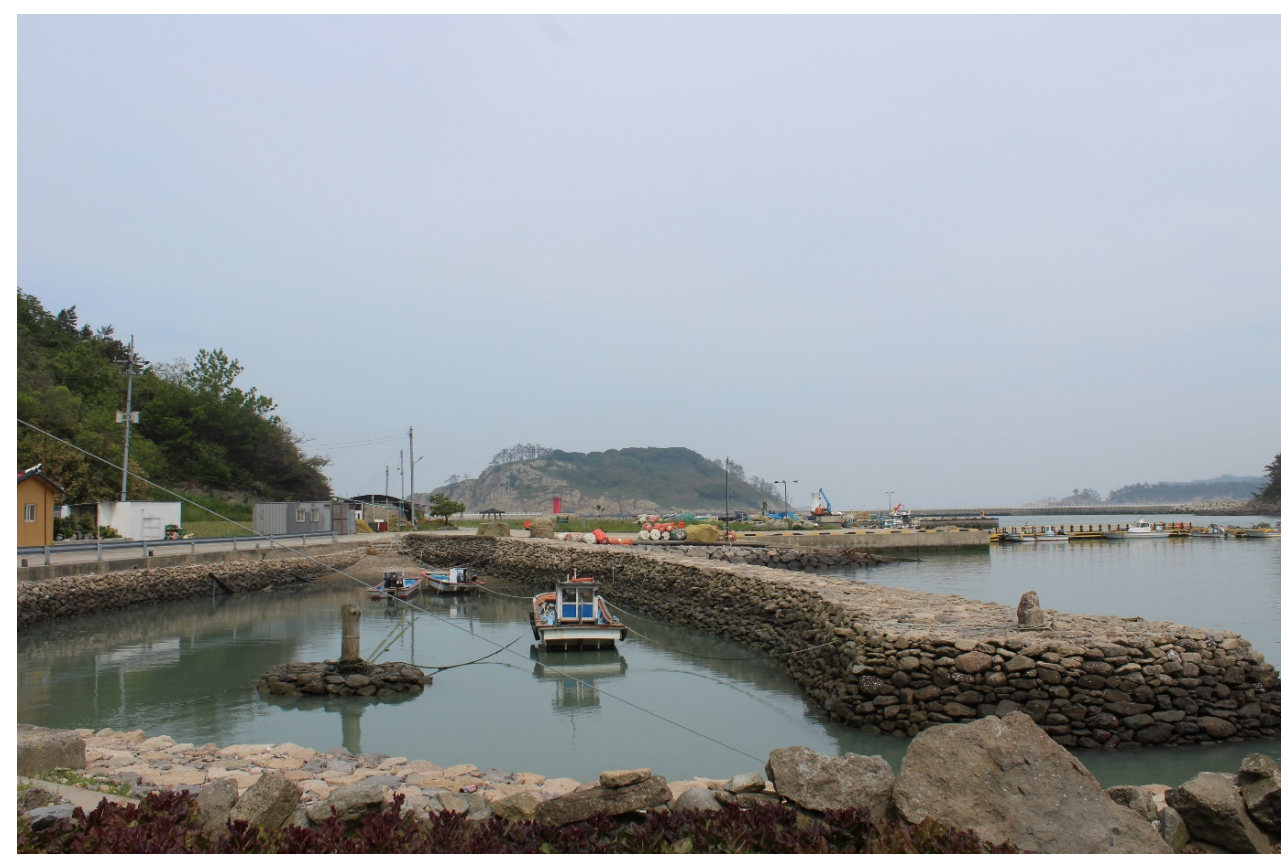

Fig 1. Traditional use of natural resource materials for harbor (photo credit: Samantha Chisholm Hatfield)

Climate change can be viewed as one underlying driver of change in animals, plants, and other aspects of nature, which in turn can affect expressions of indigenous culture. Previous work (Lynn et al 2011, McGregor 2002) has examined changes in abundance of key species in response to climate variability and change.

The goals of this research were to investigate the Traditional Ecological Knowledge, the observations, and potential adaptive strategies of island populations as they illustrated and exemplified Korean culture in a variety of formats. We 
initially expected to focus on visible expressions of culture, including songs, stories, dances, and ceremonies, but emergent results transcended those visible expressions. In the following sections we summarize our research design, our results, connections between the results and scientific literature where possible, and offer conclusions and recommendations.

\section{Research Design}

Areas of culture that are most likely affected were observed, and addressed first to draw information from structures, behaviors, events, and individuals in traditional cultural areas, such as fishing/shellfish, creative arts/music, ocean practices. From the information gathered, purposeful sampling identified key features that held important cultural knowledge and the interplay with tradition, cultural practice(s), and the natural environment. Representational information from relevant cultural areas were selected to illustrate the demonstrated TEK and possible climate change event impacts. Individuals identified as having information critical to this research study were contacted through Professor Hong. All conversations and interviews, were initiated after oral consent was obtained. Travel schedules to visit relevant cultural island sites, cultural collections, as well as individuals in coordination with staff and interviewees was established and orchestrated via Professor Hong. Visits scheduled honored recognition of pertinent traditional cultural protocols concerning timing of when it is most appropriate to discuss specific cultural topics through oral discourse.

\section{Research Questions}

The following general overarching question categories were posed when needed for prompts. Further questions evolved out of these categories depending on specific and individual cultural practices, as interviews warranted. Not all questions were asked, and some interviews none of the questions were asked because the interviewees offered information readily.

- What Traditional aspects of culture are still evident in today's society?

- What are modern day indicators of TEK?

- How are structures and/or performances maintaining TEK or adapting?

- How does the environment impact your cultural ways?

- Are there any foods/traditions/places that you cannot eat/go/practice or that have died out because of a change in the environment?

- Do climate effects shape elements of cultural value?

- Are there cultural elements (e.g., dances or seasonally relevant ceremonies) and/or cultural behaviors (e.g., prayers, ceremonial routines, symbols, songs or words) that have adapted in direct response to the presence, abundance or other characteristics of fish, wildlife, vegetation, or other aspects of the natural environment? Are there times when hunting/fishing/gathering is accompanied with certain behaviors (e.g., prayers, ceremonies or items of symbolic relevance)?

- Have traditional culture/cultural practices changed? 
- Are there aspects of tribal culture that have been evolving, identifiable by responses to climate change impacts on cultural mannerisms, traditional dress (i.e. materials, fabrics, adornment, alterations/ substitutions), areas culture is practiced/traditional spiritual practices observed? Are there traditional foods that can no longer be found or that are rarely eaten? Have any adapting measures been taken as a response to climate change impacts?

- Are there times when hunting/fishing/gathering is accompanied with certain behaviors (e.g., prayers, ceremonies or items of symbolic relevance)?

- Have adaptations occurred?

- Are there adaptations that have been made to cultural rituals, practices, or behaviors that are new or have not been traditionally practiced?

- How has Korean culture adapted to culturally traditional elemental changes? For example, are there stories that deal with the differences of "traditions" that juxtapose the "cultural ways" of old and present? Do traditional Korean stories, dances, songs, items contain elements that show differences between traditional cultural ways and present practices?

Interviews were conducted in person and notes were taken. Notation documents when taken includes translation of interviewees' inflection, intonation, pausing, and stressors of the interview they provided, including any lengthy pauses that are culturally appropriate or that convey meaning. Environmental markers and TEK indicators were earmarked.

The objectives and work incorporated Traditional Ecological Knowledge (TEK) and Ethnographic methodology of community members to guide and complete the research project through observation, cultural adhesion, semi-structured oral interviews, assessment of historical information, and artifact documentation (museums, photographs, recordings). TEK is based on observation of environmental surroundings over long periods of time and is an integral aspect of Indigenous cultural knowledge. Indigenous culture is holistic and, therefore, it is important to pair TEK with other techniques in order to achieve a fuller understanding of both the culture and the research. This project relied on social science methods which are highly efficient tools for collection and analysis of research on human subjects in Indigenous populations.

The research primarily incorporated Traditional Ecological Knowledge (TEK) as it is expressed and presented in Korean culture. TEK is based on observation of environmental surroundings over long periods of time and is an integral aspect of Indigenous cultural knowledge, particularly when populations have been living in a manner that has been closely tied to natural resources and in a communal, societal-focused manner. Indigenous culture is holistic and, therefore, it is important to pair TEK with other techniques in order to achieve a fuller understanding of the culture.

\section{Research objectives}

The overall research objective of this research was to identify and observe the behaviors and patterns of South Korean traditional culture that are or have been apparent, or those that have been shifting in abundance, collection, performance, or facilitation to the point of altering traditional cultural mannerisms. Several methods were selected to facilitate this:

1. Interviewing island elders and cultural experts from the chosen islands and classify their responses about cultural impacts viewed from a Traditional Ecological Knowledge lens.

2. Comparing responses and adaptation measures. 
This study designed to examine changes in response and attitudes about patterns and/or behaviors that have been adjusted or are in flux as a result of natural resource changes. In addition, the intent to collect and document Traditional Ecological Knowledge (TEK) as it pertains to culture was strived to be achieved. Interviewees were not asked to speculate on any patterns, terminology, climate change impacts, or consequences as a result thereof. Any causal chain linking is preliminary and would require further in-depth research to examine the depth of such and impact and/or possible adaptation measures.

\section{Results}

Our analysis of the interviews suggested three significant conclusions. As climate change can be viewed as one underlying driver of change in animals, plants, and other aspects of nature, it can in turn affect expressions of an indigenous culture. Previous work focused on America (Lynn et al 2011, McGregor 2002) has examined changes in abundance of key species in response to climate variability and change.

In the same manner as documentation with Native American tribal groups, South Korea has Indigenous populations that are disproportionately affected by climate change events. Additionally, the country has endured a colonized history as well, with cultural remnants of traditions have been maintained even during oppressive regimes. Food systems can be an indicator when examining cultural trends and shifts. During shifts and assimilations processes traditional foods often are scant; either unavailable, or considered not "acceptable" in higher classes.

1. Korean food systems seem to have been altered, and are undergoing a process of adaptation.

Korean food markets seem to have become stratified, so that more cultural foods are increasingly found on the street at vendors, as the economy grows the imported and non-traditional foods are catering to higher socioeconomic positions. Commonly accepted traditional foods such as small shelled snails, and silkworms are now being considered as outdated foods and the trend seems to be toward shying away from these traditional items. As these items are often sold at lower costs than other items in restaurants or market vendors, it marks a shift in trends and perception toward traditional food sources which are embraced. This shift also seems to indicate changes in levels of cultural stratification are underway, and non-traditional foods are nearly secluded to those of lower socioeconomic cultural status (Cheung, Tan 2007). This change in consumption impacts island populations in the resource use they have developed and use for monetary gain, as well as adjusting cultural traditional food sourcing. 


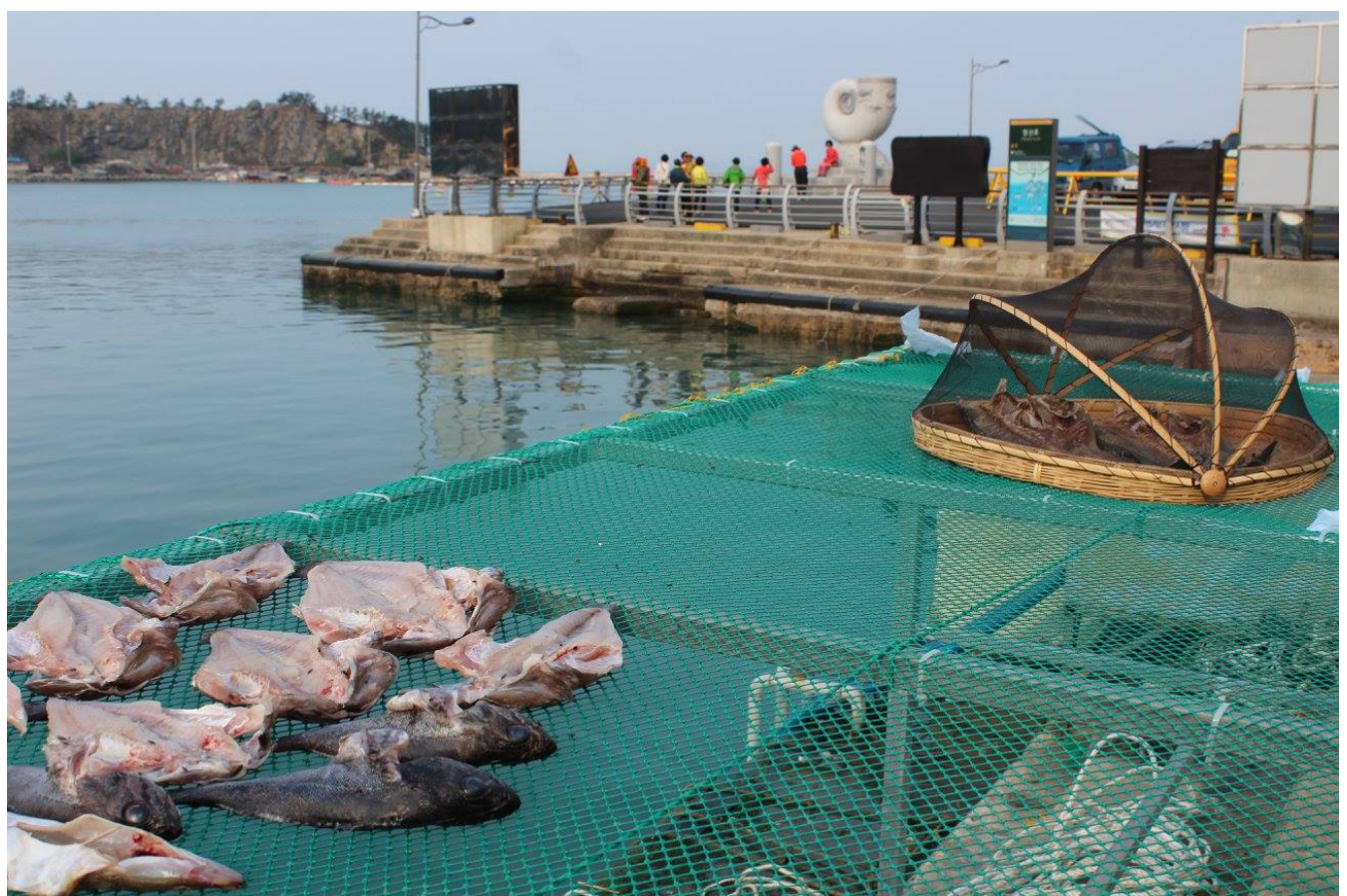

Fig 2. Fish laid out to dry in a traditional manner (photo credit: Samantha Chisholm Hatfield)

This stratification adjusts the foods collected and practices that are cultivated through island populations. Sustainable practices have been established and are routinely being utilized through crop-sharing lottery draws for seaweed farmers, or as witnessed through accounts of divers who regulate and alternate collection of resources and gathering site areas.

\section{Island populations are maintaining their TEK and the traditional culture practices distinct with rich cultural tradition and rife with TEK.}

Indications of Korean traditional culture as well as cultural natural resource reliance are still evident. The once prominent shamanistic practices have residual information systems embedded in cultural value systems and oral stories which recount medicinal remedies, that some Koreans remain adamant on utilizing (Hogarth 1999, Lee 1973). In addition, other practices were evident in utilization of environments as well as resources. Foods, plants, and spaces were accessed and utilized often as an extension of identity, and expression of cultural identity. Cultural materials were readily available and many cultural markers were seated in the environment. Outdoor performances of traditional practices were common, as were expressions of traditions. Statues, trails, markers for botanical information, even temples resided in natural elements blending in with the landscape and encouraging outdoor activities. Such placement of landmarks harks a deeper, richer tradition of TEK, where residents of a given area are more in tune with their environmental landscape than others who reside in office buildings or enclosed spaces. Most often these outdoor spaces are in areas where Indigenous populations reside, and encourage observation, and long-term observational documentation of environmental and landscape conditions is a hallmark of such groups. 


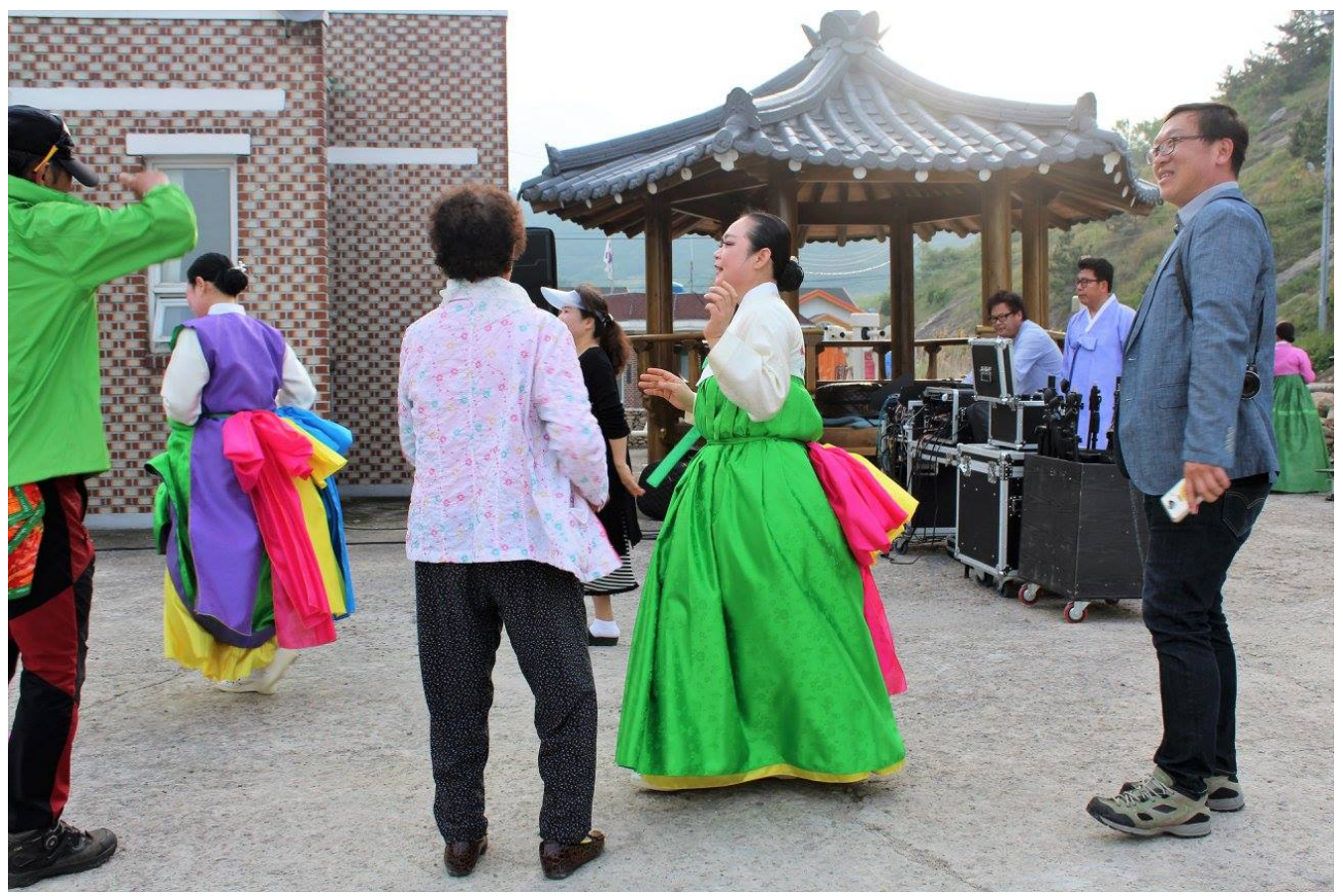

Fig 3. Traditional dancers and islanders dancing (photo credit: Samantha Chisholm Hatfield)

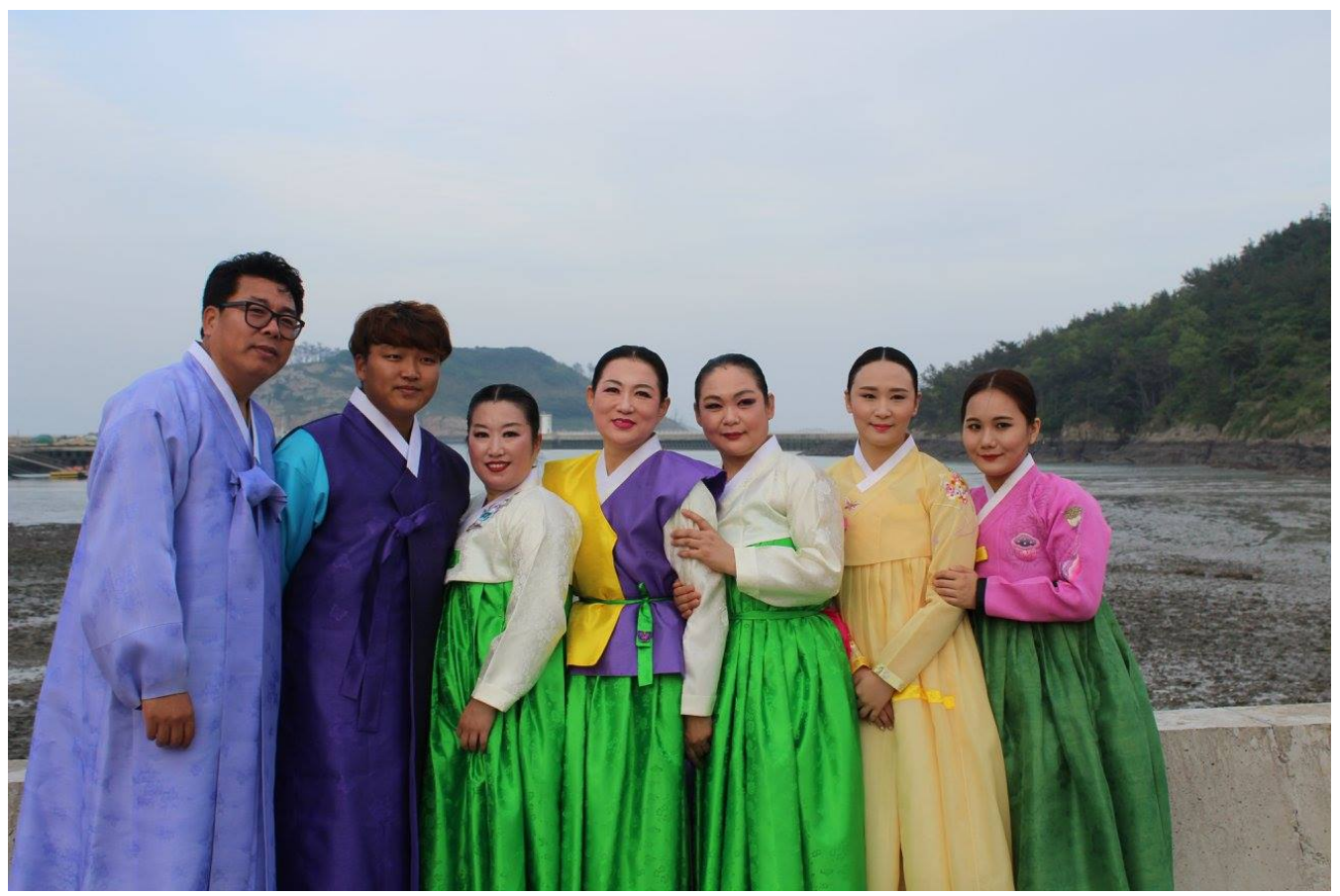

Fig 4. Traditional drummer, flautist, and dancers at island performance (photo credit: Samantha Chisholm Hatfield)

\section{Island cultures are experiencing the impact of climate change and culture change.}




\section{Interpretation analysis}

There is a strong history of Traditional Ecological Knowledge of Korean islanders, which is evidenced by their everyday living patterns, as well as the cultural aspects which are maintained. The TEK which has been established is firmly maintained and updated as needed for the living conditions of island people. It is a rich and intricate history that these island groups maintain with not only the land, but the surrounding seas. Islander practices are integrated into patterns which revolve with and around TEK as it changes and evolves.

Seasonality was a defining factor in TEK practices, as interviewees noted differences as seasons changed and the impacts on land and sea were noted. Temperature, fluctuation of wind and aspects of seasons brought about TEK behaviors as responses were appropriate. Timing of TEK was also a factor, as timelines that are linear were not as relied upon as the TEK information which is vital for a non-linear approach. This difference in utilization and TEK information has been noted in Chisholm Hatfield's previous work in Native communities, time is experienced and utilized in a manner that better fits the intiate connection these island populations have with the environments they rely and live with. Observational skills have been honed to perfection and islanders used the adaptations that have been noted to harness resources and facilitate travel as well as adjust for sustainability practices. Women divers and fishermen in particular noted the adjustment to routines and geographic areas used to collect and fish as climate change impacts have altered the natural environment. TEK patterns have been adapted and sustainability practices implemented that were rare or non-existent previously.

The incentive program instituted for collection of marine debris (Cho 2009) illustrates an awareness and focus on environmental sustainability that indicates cultural identity practices that are similarly evident amongst Native American oceanside tribes. Hong (2011) identifies many of these issues and puts forth the information caused by such fast changes in landbase issues, and touches on the cultural aspects by identifying biodiversity in landscape settings, both with human and environmental interconnectedness, as well as resource issues that are being impacted through anthropogenic issues. Hong's research excellently describes the issues Koreans face when trying to catch up with changes that have occurred, and while maintaining cultural vitality. This difficult issue presents unique problems for many cultures, but particularly those whose cultural systems are highly specified, such as the Korean islanders, as they have been, or remain being, tied to land or sea as intimate components of cultural identity. "Traditional land use practices based on 'Fengshui' have significantly contributed to human-mediated patterns of landscape changes, in addition to the role of the socio-economic background (development) and other human activities." (Hong, Song, Wu 2006) articulately illustrates the basis that the environment has on cultural adherence, as well as the need for further examination of cultural patterns occurring due to climate change events, and how individuals are adjusting to those forced environmental changes. Because climate change events have been increasing, individuals must also increase their responsive behaviors, and addressing these changes through research is highly valuable.

Islanders all illustrated a high degree of sustainability efforts, and awareness of interpreting and analyzing natural resource levels in their marine and landbase environments. Interviews and observations all returned similarly effective and accurate descriptions and responsive behaviors. Concerns about overharvesting resources remained a consistent pattern amongst all island populations, as climate change events impact tides and water quality. Other factors which have been attributed to climate change events have been movement patterns and adjusting to encroachment of outside individuals and groups which have begun to harvest and impact resources islanders have depended, and still remain 
dependent on for their income and survival. This knowledge and sustainability efforts also facilitates an understanding and maintenance of culture which has a depth that is not evident on mainland areas. The cultural richness that is documented is evident within island cultures, and is well maintained, in large part because of the TEK and islanders' sustainability practices.

As is commonly seen with cultural populations who are closely tied to the land and/or the sea, knowledge is intricately enmeshed within Traditional Knowledges which are passed through generations. The TEK information Korean islanders have exhibited during this research project is evident and closely cared for, maintaining a high degree of information in multiple areas, that are often overlapping. These populations hold the key to maintenance as modern influences can erode and fracture cultural adherences. These cultures' knowledge are key to a structure of continuance, as well as facilitating a feasible and successful sustainability practice that is effective and maintains a strong cultural identity at the same time.

The increase of tourism that islands are experiencing is evidence that many mainland Koreans are appreciating and reconnecting to cultural mannerisms and traditions that are readily available and evident on islands. Rich cultural events are displayed and traditions are displayed through everyday life, supporting and upholding cultural practices that have been overshadowed with mainland practices and the rapid growth of adjustment that economic booms have brought to the region. While islands utilize and benefit from the same economy, the removal from large corporation and city establishments allow them to maintain and in some instances, cultivate rich traditional heritages, honing and adjusting to environmental conditions as to perfect the sustainability efforts that maintain a way of life that is reliant on the environment.

It is not surprising that as information increases regarding climate change and impacts that are affecting natural resources, that islanders are maintaining and the first line of defense as being the key to successful sustainability practices. It is also not surprising that travel to island areas is increasing and pressure from non-islanders is weakening the systems that have been established for sustainability, and commerce from travel is replacing the cultural mannerisms islanders have been utilizing. Culture is a valuable resource that also must be addressed and protected as effects from environmental systems are altered and adjust to modern impacts, of which have never been noted or had to be taken into account for until recently. These adjustments to climate change events are to look to cultures such as island cultures to note their manifestation of effectiveness and wisdom that is earned from generations of Traditional Ecological Knowledge put into practice, to ensure sustainability for everyone. 


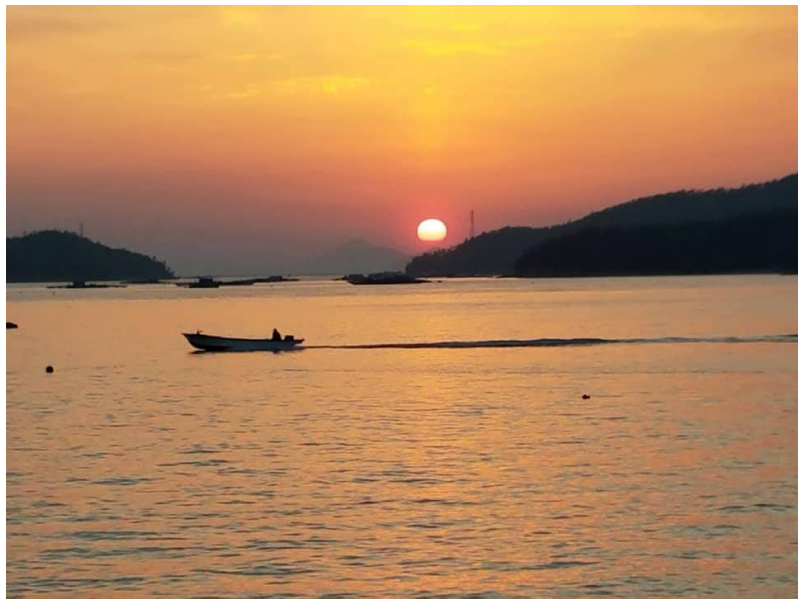

Fig 5. Traditional fisherman at sunset (photo credit: Samantha Chisholm Hatfield)

\section{Conclusions and recommendations}

Korean culture is highly unique, and holds a distinguishing aspect amongst Asian societies. Too often it is intermingled and associated with surrounding countries because of the lack of information determining the culture's uniqueness. Because of the changing systems which have been forced upon Korean traditional culture in relatively short time spans, it is essential to understand the effects which have taken place, and how land has been utilized, the role environment plays currently and has played, to better assess the aspects of culture that are vulnerable.

There is ample evidence that merging TEK with western science is a research model that yields important results in the area of climate change research (for review see Riedlinger and Berkes 2001, Huntington 2000, Cruikshank 2001) and natural resource management (for review see Pinkerton 1989, Berkes 1991) This research work integrated TEK from Korean island individuals to achieve a more holistic view of climate change outcomes on culture and cultural practices on islands than other approaches alone offer. Since the island populations are the first line of impact, they are witnessing a change in environmental conditions which is likely due to climate change events impacts, as such, these research results could provide information for other Korean agencies dealing with resource and climate change issues, for the betterment of Korean society. Infrastructure, policy development, and evaluation for future planning on various levels can utilize this information to best assist the Korean population and maintain sustainability of the rich beautiful Korean culture. 


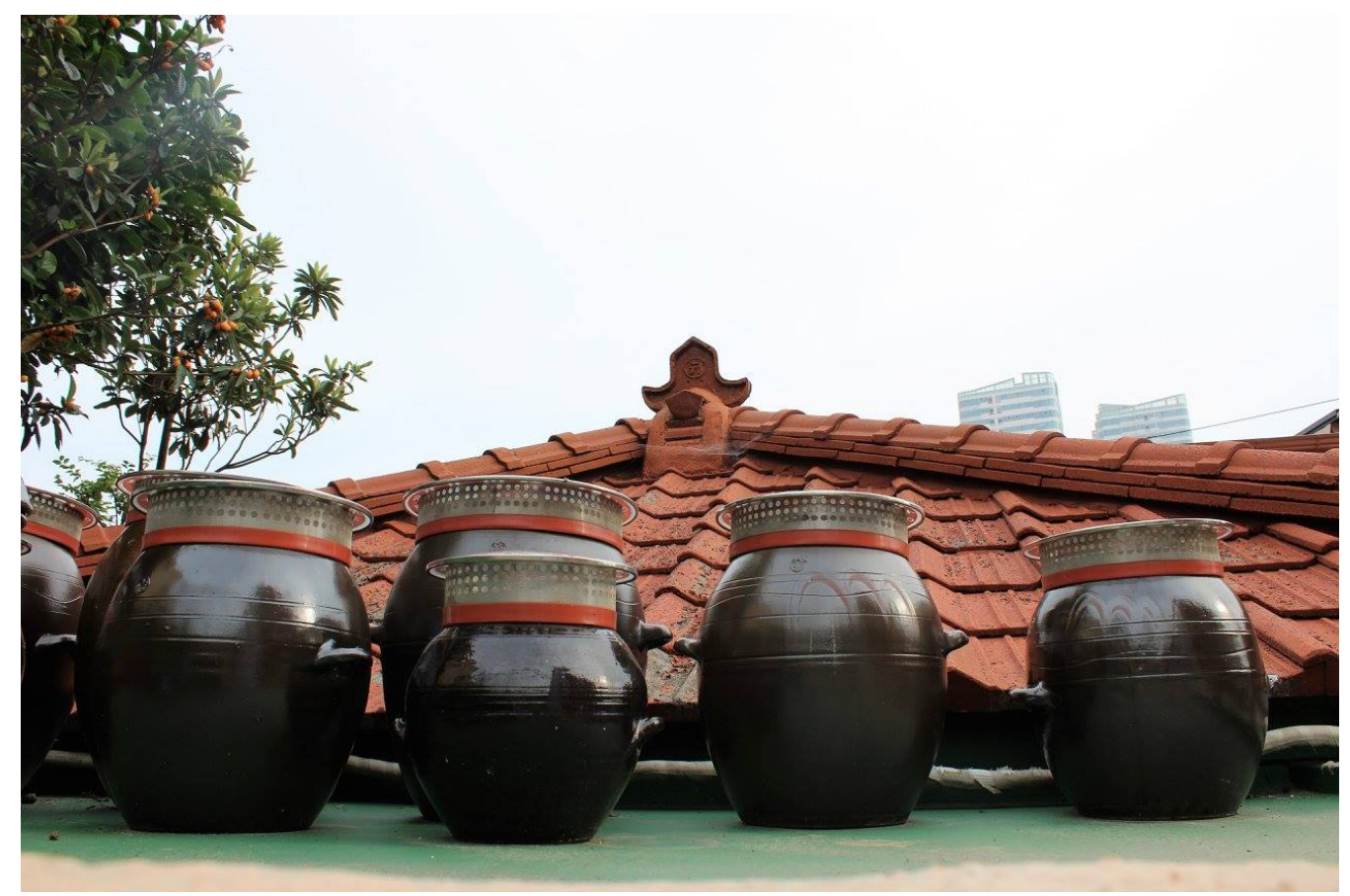

Fig 6. Traditional kimchi pots (photo credit: Samantha Chisholm Hatfield)

\section{Acknowledgements}

This manuscript is a research conducted with the support of National Research Foundation of Korea (NRF-2009-361A00007) funded by Korean government (Ministry of Education, Science and Technology) in 2009. Special thanks to the Korea Foundation for the supporting field research fellowship to Dr. Samantha Chisholm Hatfield.

We also would like to thank Prof. Mi-Jung An of the Korea Maritime and Ocean University, Mr. Kyoung-Wan Kim and Mrs. Mi-ra Cho of Mokpo National University for their helping of island survey and giving valuable discussion. 


\section{Appendix}

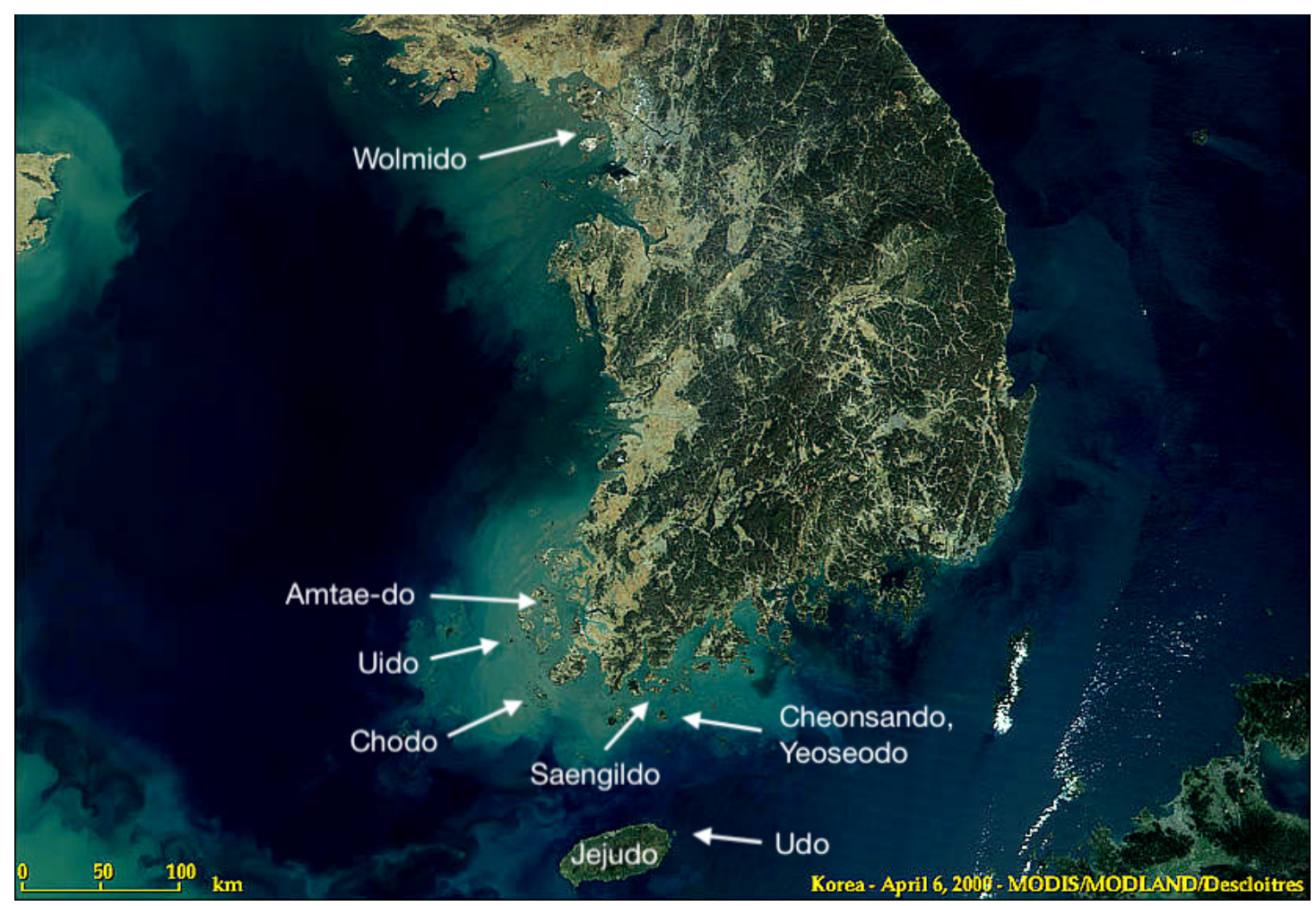

Islands visited for this research: Cheonsando, Yeoseodo, Uido, Chodo, Wolmido, Jeju, Udo, Amtae-do, and Saengildo.

\section{References}

Adger, W.N., 2006. Vulnerability. Global environmental change, 16(3), pp.268-281.

Adger, W.N., Huq, S., Brown, K., Conway, D. and Hulme, M., 2003. Adaptation to climate change in the developing world. Progress in development studies, 3(3), pp.179-195.

Antone, Joseph R., 2013. The Use of Traditional Ecological Knowledge in Contemporary Environmental Policy. Sociological Imagination: Western's Undergraduate Sociology Student Journal. Vol.2 (1), Article 5, 1-11.

Basso, Keith H., 1996. Wisdom Sits in Places. University of New Mexico Press. Albuquerque, New Mexico.

Berkes, Fikret, 1999. Sacred Ecology. Taylor \& Francis. Philadelphia, Pennsylvania.

Berkes, F., 2004. Rethinking community-based conservation. Conservation biology, 18(3), pp.621-630.

Berkes, F., Colding, J. and Folke, C., 2000. Rediscovery of traditional ecological knowledge as adaptive management. Ecological applications, 10(5), pp.1251-1262. 
Cajete, Gregory. 2000. Native Science Natural Laws of Interdependence. Clear Light Publishers. Santa Fe, New Mexico.

Cheung, S. and Tan, C.B. eds., 2007. Food and foodways in Asia: Resource, tradition and cooking (Vol. 2). Routledge.

Cho, D.O., 2009. The incentive program for fishermen to collect marine debris in Korea. Marine Pollution Bulletin, 58(3), pp.415-417.

Colombi, B.J., 2012. Salmon and the adaptive capacity of Nimiipuu (Nez Perce) culture to cope with change. The American Indian Quarterly, 36(1), pp.75-97.

Füssel, H.M., 2007. Vulnerability: A generally applicable conceptual framework for climate change research. Global environmental change, 17(2), pp.155-167.

Gadgil, M., F. Berkes, and C. Folke. 1993. Indigenous knowledge for biodiversity conservation.

Hogarth, H.K.K., 1999. Korean shamanism and cultural nationalism. Jimoondang Publishing Company.

Hong, S.K., 2011. Biocultural diversity and traditional ecological knowledge in island regions of Southwestern Korea. Journal of Ecology and Environment, 34(2), pp.137-147.

Hong, S.K., Song, I.J. and Wu, J., 2007. Fengshui theory in urban landscape planning. Urban ecosystems, 10(3), pp.221-237.

Hong, S.K., Wu, J., Kim, J.E. and Nakagoshi, N. eds., 2010. Landscape ecology in Asian cultures. Springer Science \& Business Media.

Hong, S.K. 2012. Tidal-flat islands in Korea: exploring biocultural diversity. Journal of Marine and Island Cultures, 1(1), 11-20.

International Conference on Biological and Cultural Diversity, 2010. "Working document on a proposed joint programme of work on biological and cultural diversity led by the Secretariat of the Convention on Biodiversity and UNESCO".

Kassam, K.A.S., 2009. Biocultural diversity and indigenous ways of knowing: human ecology in the Arctic. University of Calgary Press.

Lee, J.Y., 1973. Concerning the origin and formation of Korean shamanism. Numen, 20(Fasc. 2), pp.135-159.

Lee, S. and Paik, H.S., 2011. Korean household waste management and recycling behavior. Building and Environment, 46(5), pp.1159-1166.

Lichatowich, J. and Lichatowich, J.A., 2001. Salmon without rivers: a history of the Pacific salmon crisis. Island Press.

Lynn, K., MacKendrick, K. and Donoghue, E.M., 2011. Social vulnerability and climate change: synthesis of literature.

Kim, D.K., 2006. The natural environment control system of Korean traditional architecture: comparison with Korean contemporary architecture. Building and environment, 41(12), pp.1905-1912.

Kim, E.M. and Ryoo, J., 2007. South Korean culture goes global: K-Pop and the Korean wave. Korean social science journal, 34(1), pp.117-152. Kim, I., 2016. Land Reform in South Korea under the US Military Occupation, 1945-1948. Journal of Cold War Studies.

Marino, E. and Ribot, J., 2012. Special issue introduction: adding insult to injury: climate change and the inequities of climate intervention.

McGregor, D., 2002. Indigenous knowledge in sustainable forest management: Community-based approaches achieve greater success. The forestry chronicle, 78(6), pp.833-836.

Mote, P.W., Parson, E.A., Hamlet, A.F., Keeton, W.S., Lettenmaier, D., Mantua, N., Miles, E.L., Peterson, D.W., Peterson, D.L., Slaughter, R. and Snover, A.K., 2003. Preparing for climatic change: the water, salmon, and forests of the Pacific Northwest. Climatic change, 61(1), pp.45-88.

Qin, H., 2011. Karim-Aly S. Kassam: Biocultural diversity and Indigenous ways of knowing: Human ecology in the Arctic. Human Ecology, 39(2), pp.233-234.

Rapport, D.J., 2007. Sustainability science: an ecohealth perspective. Sustainability Science, 2(1), pp.77-84. 
Sector, U.E., 2005. United Nations Decade of Education for Sustainable Development (2005-2014): International Implementation Scheme. UN Educ Sci Cult Organ UNESCO Paris Fr.

UNESCO Declaration on Cultural Diversity, 2001. http://unesdoc.unesco.org/images/0012/001271/127160m.pdf

UNESCO, 2010. UNESCO World Report: Investing in Cultural Diversity and Intercultural Dialogue.

Whittaker, R.J. and Fernández-Palacios, J.M., 2007. Island biogeography: ecology, evolution, and conservation. Oxford University Press.

Whyte, Kyle Powys. 2014. Justice forward: Tribes, climate adaptation and responsibility. Climate Change and Indigenous Peoples in the United States, pp. 9-22.

Wildcat, Daniel R. (2014). Introduction: climate change and indigenous peoples of the USA. Climate Change and Indigenous Peoples in the United States, pp 1-7.

Yang, Hyinan, Ed. (2013). Law and Society in Korea. Edward Elgar Publishing.

Zent, S., 2009. Methodology for developing a vitality index of traditional environmental knowledge (VITEK). Caracas (VE): Instituto Venezolano de Investigaciones Cientificas. 